Linköping studies in health sciences, Thesis No. 128

\title{
Health Economic Aspects of Injury Prevention at the Municipal Level
}

\author{
Harald Gyllensvärd
}

Division of Community Medicine

Department of Medical and Health Sciences

Linköping University, Sweden

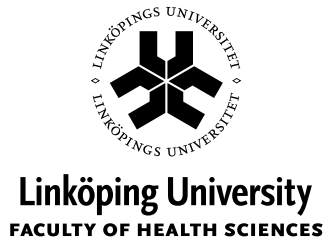

Linköping 2014 
(CHarald Gyllensvärd, 2014

Published article has been reprinted with the permission of the copyright holder.

Printed in Sweden by LiU-Tryck, Linköping, Sweden, 2014

ISBN: 978-91-7519-351-9

ISSN: 1100-6013 
To my beloved family

Dubium sapientiae initium. Doubt is the origin of wisdom. René Descartes 



\section{ABSTRACT}

Unintentional injuries are a global health problem, which in 1996 was estimated to cause up to 3 million deaths per year. In Sweden, about 4,600 people die annually due to external causes of morbidity and mortality (injuries and poisoning). Among children 1 to 17 years old, injuries are the leading cause of death in Sweden for both boys and girls. Injuries are also the leading cause of life years lost before age 65 in men and the second most common in women.

Injury prevention interventions and programs can be implemented to mitigate the magnitude of this public health problem, the number of injuries in society, and the substantial costs associated with injuries. Society's resources are however limited and therefore it is pivotal that interventions are cost-effective and not only effective: that is, that they provide good value for money.

Hence, the aim of this thesis was to develop new knowledge and improve decision making by elaborating on some of the important health economic aspects of injury prevention. Consequently, a critical appraisal of the existing cost-effectiveness studies on injury prevention interventions and estimations of the societal costs for different types of injuries that needed medical attention were conducted. The critical appraisal of studies was limited to those studies that investigated interventions that could be implemented by municipalities. The results shows that injuries are associated with substantial societal costs but differ considerably between different types of injuries. The average cost per injury was estimated at $€ 2,726$ and varied between $€ 892$ and $€ 15,537$. Furthermore, the results indicate that there are injury prevention interventions that offer good use 
of societal resources. However, there is a general lack of economic evidence surrounding injury prevention interventions.

This thesis has expanded the knowledge in some important health economic aspects of injury prevention. The generated knowledge may advantageously be used in future research, including cost-effectiveness analyses of injury prevention interventions, and assist in the targeting of new research. Future research should focus on estimating the cost-effectiveness of different interventions and the reductions in quality of life due to different injuries. Costeffectiveness data help decision-makers make judiciously resource allocation decisions that maximise health gain given limited budgets. 


\section{LIST OF PAPERS}

I. Harald Gyllensvärd

Cost-effectiveness of injury prevention - a systematic review of municipality based interventions.

Cost Eff Resour Alloc (2010) 8, 17.

II. Harald Gyllensvärd

The societal costs of injuries: estimating the incidence and cost for different types of injuries in Sweden. Submitted. 


\section{ABBREVIATIONS}

CEA Cost-Effectiveness Analysis

CPI Consumer Price Index

CPP Cost Per Patient

EBM Evidence-Based Medicine

GDP Gross Domestic Product

HEE Health Economic Evaluation

HTA Health Technology Assessment

ICD-10 International Classification of Diseases, 10th version

ICER Incremental Cost-Effectiveness Ratio

IDB Injury Database

IMF International Monetary Fund

OECD The Organisations for Co-operation and Development

PPP Purchasing Power Parity

QALY Quality Adjusted Life Years

RCT Randomised Controlled Trial

SG Standard Gamble

SNBHW Swedish National Board for Health and Welfare (Socialstyrelsen)

SSIA The Swedish Social Insurance Agency

TTO Time-Trade Off

VAS Visual Analogue Scale

WHO World Health Organisation 


\section{CONTENTS}

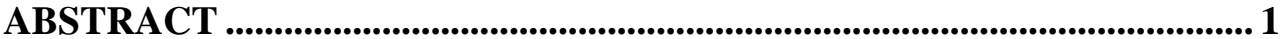

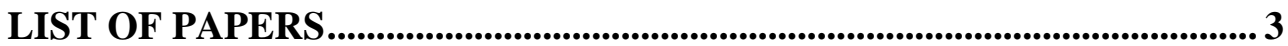

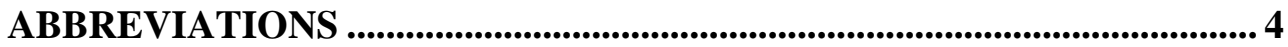

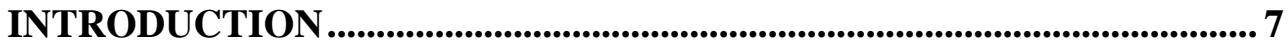

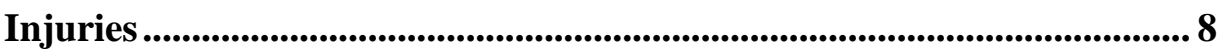

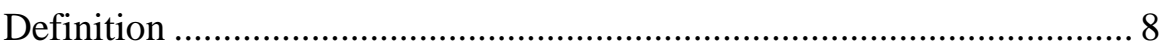

Morbidity and mortality .................................................................... 10

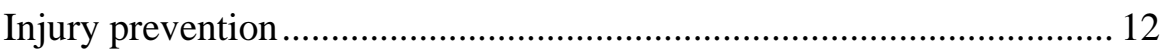

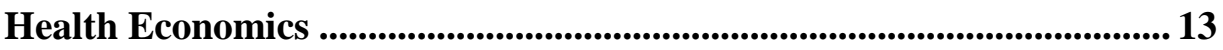

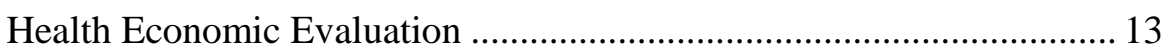

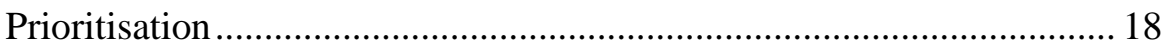

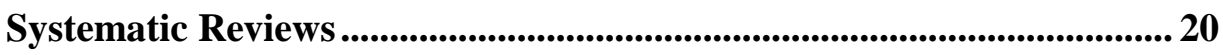

AIMS

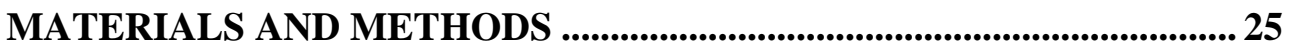

Cost-effectiveness of injury prevention (study I)....................................... 25

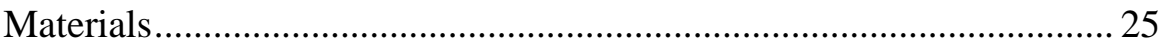

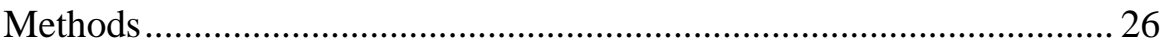

The societal costs of injuries (study II) ............................................................ 28 


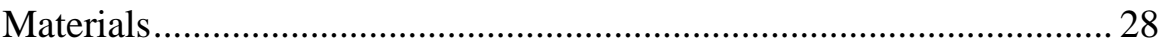

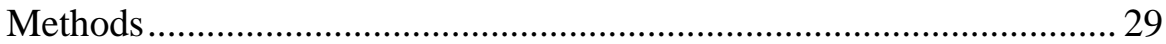

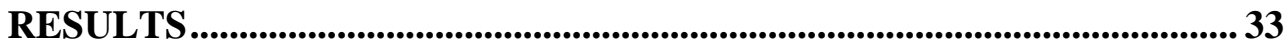

Cost-effectiveness of injury prevention (study I)......................................... 33

The societal costs of injuries (study II) .............................................................. 35

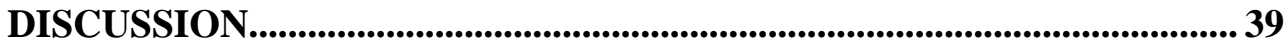

Main findings...................................................................................................................... 39

Strengths and weaknesses .....................................................................................39

Cost-effectiveness of injury prevention (study I) ................................... 39

The societal costs of injuries (study II) ................................................. 42

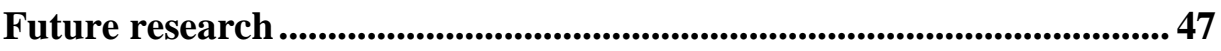

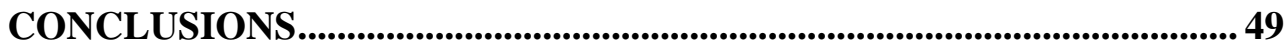

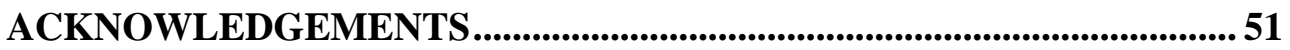

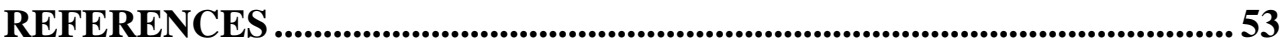




\section{INTRODUCTION}

Injuries are a global health problem. WHO estimate that injuries and violence kill more than five million people worldwide annually and that they account for $9 \%$ of global mortality [1]. It is also estimated that injuries account for $14 \%$ of global life years lost when using the measure Years of Life Lost [2]. In Sweden, about 4,600 people die annually due to "External causes of morbidity and mortality (injuries and poisoning)," according to the Cause of Death Register [3]. Among children 1 to 17 years with boys and girls alike, injuries are the leading cause of death in Sweden [4]. Injuries are also the leading cause of life years lost before age 65 in men and the second most common in women [4]. The Swedish Civil Contingencies Agency (MSB) has estimated the societal costs for all accidents in 2005 to SEK 59 billion [5].

Injury prevention interventions can be implemented to reduce the number of injuries and their impact on health. It is important that these interventions are cost-effective to justify their implementation. If they are not cost-effective they should not be implemented because the resources available could be better spent elsewhere.

Cost-effectiveness can be estimated by using health economic methods in which economic theory is applied on health. One of the main goals in health economics is to assist decision makers in their decisions on how to best use scarce resources (resource allocation) so that maximum outcome is obtained. Often this means maximising health outcome. 
Cost-effectiveness and the parts to estimate cost-effectiveness is also something others point out as important. For instance, Currie et al. concludes that they think "research funds would be better spent (...) through estimation of the effectiveness, costs, and benefits associated with different injury prevention strategies" [6].

This thesis has focused on some important health economic aspects related to injury prevention, including the cost-effectiveness of different interventions and the costs associated with different types of injuries.

\section{Injuries}

This section briefly discuss the morbidity and mortality of injuries after defining them and the different types of care.

\section{Definition}

Injuries can be defined in different ways and one way is the definition by Baker et al., which Pless and Hagel cite: "'Injury is the transfer of one of the forms of physical energy (mechanical, chemical, thermal, etc.) in amounts or at rates that exceed the threshold of human tolerance." It may also result from lack of essential energy such as oxygen (for example, drowning) or heat (for example, hypothermia)." $[7,8]$.

Injuries can also be defined as a diagnosis in the International Statistical Classification of Diseases and Related Health Problems 10th Revision Version for 2010 (ICD-10). Injuries are included in chapter XIX: Injury, poisoning and 
certain other consequences of external causes (S00-T98) [9]. The existing diagnoses are shown in groups in Table 1.

Table 1. Diagnoses included in Chapter XIX in ICD-10.

\begin{tabular}{|c|c|}
\hline ICD-groups & Diagnosis \\
\hline S00-S09 & Injuries to the head \\
\hline S10-S19 & Injuries to the neck \\
\hline S20-S29 & Injuries to the thorax \\
\hline S30-S39 & Injuries to the abdomen, lower back, lumbar spine and pelvis \\
\hline S40-S49 & Injuries to the shoulder and upper arm \\
\hline S50-S59 & Injuries to the elbow and forearm \\
\hline S60-S69 & Injuries to the wrist and hand \\
\hline S70-S79 & Injuries to the hip and thigh \\
\hline S80-S89 & Injuries to the knee and lower leg \\
\hline S90-S99 & Injuries to the ankle and foot \\
\hline T00-T07 & Injuries involving multiple body regions \\
\hline T08-T14 & Injuries to unspecified part of trunk, limb or body region \\
\hline T15-T19 & Effects of foreign body entering through natural orifice \\
\hline T20-T32 & Burns and corrosions \\
\hline T20-T25 & Burns and corrosions of external body surface, specified by site \\
\hline T26-T28 & Burns and corrosions confined to eye and internal organs \\
\hline T29-T32 & Burns and corrosions of multiple and unspecified body regions \\
\hline T33-T35 & Frostbite \\
\hline T36-T50 & Poisoning by drugs, medicaments and biological substances \\
\hline T51-T65 & Toxic effects of substances chiefly nonmedicinal as to source \\
\hline T66-T78 & Other and unspecified effects of external causes \\
\hline T79-T79 & Certain early complications of trauma \\
\hline T80-T88 & Complications of surgical and medical care, not elsewhere classified \\
\hline T90-Т98 & Sequelae of injuries, of poisoning and of other consequences of external causes \\
\hline
\end{tabular}

Injuries can also be treated in different types of care. In this thesis, three types of care are used: Inpatient, outpatient and primary care. A patient who is admitted to a hospital or clinic for treatment that requires at least one overnight stay is referred to as an inpatient patient [10]. A patient who is admitted to a hospital or clinic for treatment that does not require an overnight stay is referred to as an 
outpatient patient [10]. A patient that visits a health center for primary care is referred to as a primary care patient.

\section{Morbidity and mortality}

\section{Morbidity}

Figure 1 shows trends in the number of inpatient patients for the diagnostic groups S00-S99 and S00-T98 per 100,000 inhabitants between 1998 and 2012 for men and women, in Sweden. The figures fluctuates from year to year but are relatively stable over time. Injuries are about $7 \%$ more common on average among women than among men and varies between $5 \%$ and $10 \%$ in this inpatient statistics including all ages between 1998 and 2012 [11].

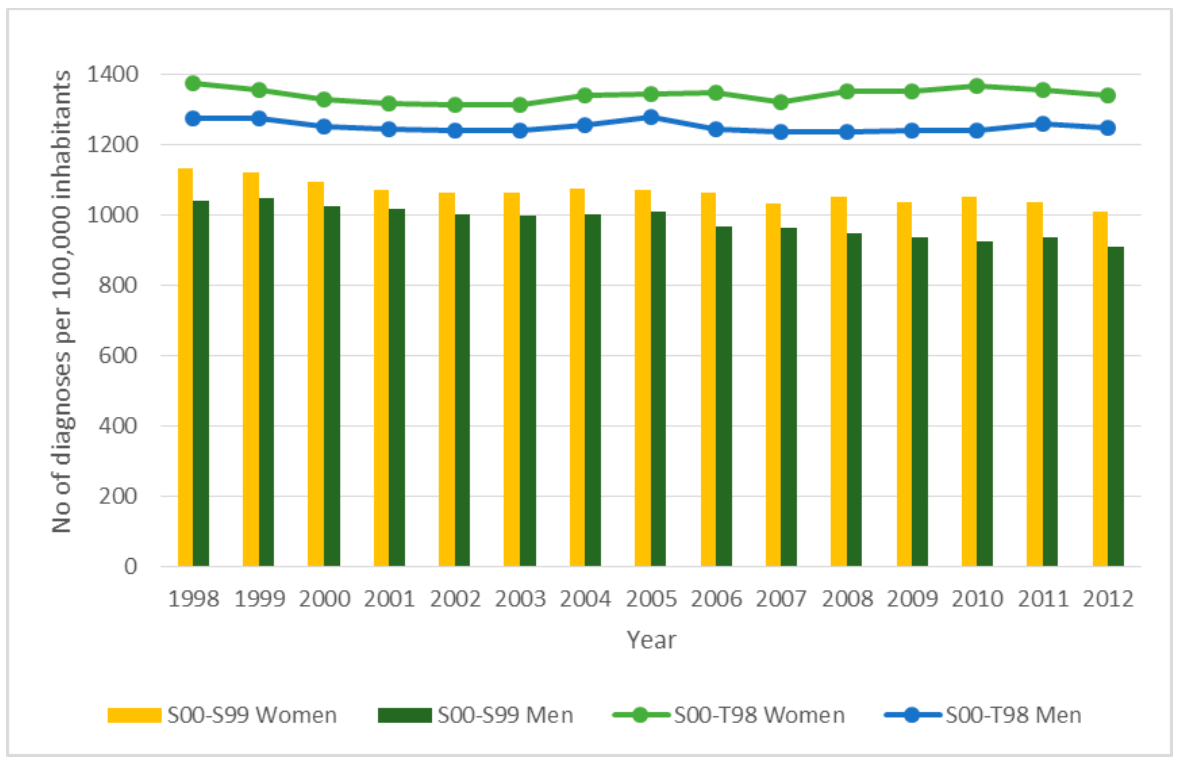

Figure 1. Diagnoses in inpatient care, number of patients/100,000 inhabitants, S00-S99 (Injuries to individual body parts) and S00-T98 (Injury, poisoning and certain other consequences of external causes), Sweden, Age: 0$85+[11]$. 
For outpatient and primary care there exist no good comprehensive national statistics. For outpatient care there exist a database called IDB (Injury Database). In IDB data is collected from a number of hospitals in Sweden, which together in 2010 had a national coverage of about 7\% [12]. The database is valuable because it includes a lot of information about the context in which injuries occur. From IDB-data the number of outpatient patients per 100,000 inhabitants can be estimated to 7,771; 6,266; and 7,019 for men, women, and on average for 2010 [12].

For primary care there are some county councils that have data for the catchment area they are responsible for. Gyllensvärd has made national estimations based on data from Östergötland County Council for diagnoses S00S99. From the data provided the incidence of people seeking medical attention in primary care can be estimated to 2,314 patients per 100,000 inhabitants and year [13].

From the same data the proportions on the number of patients seeking medical attention per type of care can be estimated to $11 \%, 64 \%$, and $25 \%$ for inpatient, outpatient, and primary care visits, respectively, for the diagnoses S00-S99 [13].

\section{Mortality}

Figure 2 shows trends in the number of deaths due to injuries and poisoning per 100,000 inhabitants between 1997 and 2012 for men and women, in Sweden. As in the morbidity statistics the figures fluctuates from year to year but are relatively stable over time. In contrast to the inpatient statistics men face an increased risk of dying compared to women that varies between $58-79 \%$, with an average of $71 \%$ higher risk than women over this time period [3]. 


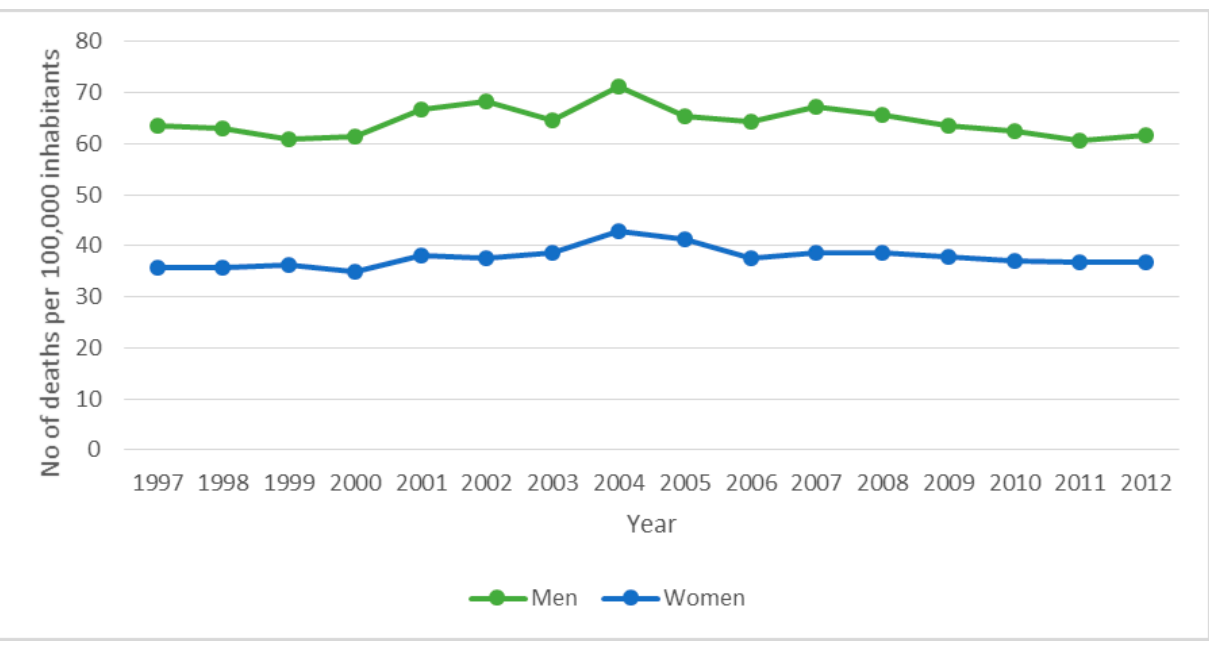

Figure 2. Cause of Death Statistics, Number of deaths per 100,000, V01 Y98 External causes of morbidity and mortality (injuries and poisoning), Sweden, Age: 0-85 + [3].

\section{Injury prevention}

Prevention can be classified into primary, secondary, and tertiary prevention strategies. Primary prevention aims at preventing injuries from occurring; secondary prevention aims at mitigating the consequences from injury; and tertiary prevention aims at influencing the outcome of the injury after the injury has occurred and this is sometimes labelled injury control [7].

Injuries occur at different places and among different people. This is why injury prevention interventions have different strategies and target different areas and people. For instance, WHO has created Safe Communities as a way of combatting injuries locally. The core of the Safe Community model is collaboration, partnership, and community capacity building [14]. It is beyond the scope of this thesis to describe the model in detail and all the other prevention strategies. An overview of community based injury prevention strategies is available elsewhere, for instance in a dissertation by Nilsen [15]. 


\section{Health Economics}

Health economics has been described by Folland et al. as: "Health economics studies how resources are allocated to and within the health economy" [16]. In this thesis the main focus is to study some of the health economic aspects of injury prevention which narrows down the scope to aspects of health economic evaluation (HEE) and decision-making related to this.

\section{Health Economic Evaluation}

The point of departure is that all resources are limited and always can be used for alternative spending. If resources are limited then we need to spend them wisely to maximise societal benefit. HEE deals to a great extend with these problems and can assist in fulfilling the objective of maximising societal benefit given limited resources. HEE can also be defined as the comparison of alternative options in terms of their costs and consequences [17]. Consequently, we need information about the alternative option, the costs associated with the options, and the consequences for both options to be able to do this comparison.

The choice of an alternative is, thus, a pivotal part in the analysis and in the interpretation of the results. When a comparison option (or several options) has been chosen the objective is often to estimate the incremental cost-effectiveness ratio (ICER). The exceptions to this is the cost-minimisation analysis - in which only the costs are compared (this analysis is used when the effects are deemed equivalent) - and the cost-benefit analysis, in which all costs and effects are valued in monetary terms and a net present value is estimated. The ICER is estimated by dividing the differences in costs with the differences in effects 
between the alternatives. The costs include all relevant costs which could include the costs for the different treatments, the costs for resource use after treatment, and eventual changes in productivity; for instance, one treatment could lead to less health care visits and improved productivity in the future. The effects differ between treatments for different diagnoses. Using different effect variables for different disease areas make however horizontal prioritising impossible. Therefore a common effect variable is desirable. Theoretically, a cost-benefit analysis, in which all effects are valued in monetary terms, seems like a good approach because one can directly see if the benefits are higher than the costs. In practice there are however difficulties in eliciting monetary values with high validity for all effects. Hence, many recommend using quality adjusted life years (QALYs) as the effect measure to make the ICER comparable between disease areas; to name just a few organisations recommending QALYs: National Institute for Health and Care Excellence (NICE) and the Swedish Dental and Pharmaceutical Benefits Agency (TLV) $[18,19]$. In the literature a cost-effectiveness analysis using QALYs as an outcome measure is often referred to as a cost-utility analysis.

\section{Costs}

Costs is a pivotal part in economic evaluation and is thus essential to include. To estimate the costs there is a need for identifying, measuring, and valuing all resource changes associated with an intervention or treatment [20]. Resource changes should be valued at their opportunity cost. Which costs to include are also determined which perspective the evaluation has [17, 20-25]. When employing a health provider perspective then only the costs relevant for the health provider should be included. Similarly, when employing a societal perspective all relevant costs should be included. Costs or benefits that appear in the future should be discounted to present values to facilitate comparisons. 
Costs are also often divided into direct and indirect costs [17]. Intangible costs are also sometimes used and they refer to "consequences that are difficult to measure and value, such as the value of improved health per se, or the pain and suffering associated with treatment" [17]. Direct costs has been defined as including "the value of all the goods, services, and other resources that are consumed in the provision of an intervention or in dealing with the side effects or other current and future consequences linked to it" [21]. Indirect costs often refers to production loss due to sickness. The costs are "associated with lost or impaired ability to work or to engage in leisure activities due to morbidity and lost economic productivity due to death" [21].

Cost of illness studies deploys costing methods to estimate the total costs for a specific disease. This is something different from only looking at the changes in costs in an economic evaluation studying the consequences of alternating the exposure - for instance, in form of a treatment or an intervention - in a specific subpopulation. Cost of illness studies can draw attention to a specific disease area - as can prevalence and incidence figures - and provide information about the magnitude of the problem. This is probably why they are fairly popular to conduct. The value of cost of illness studies is, however, contentious [6, 26] because they provide little guidance on the cost-effectiveness of specific interventions. For instance, it is often wiser to spend money on minor disease burden problems than bigger ones if it exists cost-effective interventions mitigating the former problem but not the latter one. Cost of illness studies can however provide valuable information about costs that can be used as an input in cost-effectiveness analysis. 
Costs can also be estimated by different degrees of refinement. Terms like "bottom-up" or "top-down" and gross versus micro-costing circulate in the literature. They relate to which level cost estimations are based on. Where to land in the continuum between the endpoints of gross and micro-costing is much a trade-off between the desirable precision and the time cost for collecting the information. Data availability is also a factor in that decision. Brouwer et al. writes that "in practice most economic evaluations use a combination of these methods for different parts of a study" [20].

Disease costs can further be estimated by deploying the prevalence or the incidence method [27]. In the prevalence method costs incurred by all diseased individuals at a certain time interval - for instance one year - are estimated. In the incidence method all costs and future costs related to all individuals incurring the disease during a time period - usually one year - are estimated. There are advantages and disadvantages with the two methods which are discussed in, for instance, Tarricone and Segel [28, 29].

Valuing production loss is also something which are done differently, which of course yield different results. The human capital approach [30,31] - in which production loss is valued at the cost of labour - is probably the most common approach. The proponents of the friction cost method [32-34] argues for that production loss is likely to be lower than in the human capital approach due to a number of reasons, including that individuals can be replaced from a pool of unemployed people and some "work can be made up for the sick employee on his return to work" [33]. The friction cost method has been criticised for not being consistent with economic theory [35]. Others have argued that team production can be influenced if individuals are absent and found in a studied sample that the median cost was $28 \%$ greater than a worker's daily wage [36]. 
There are probably more methods to value production loss because it is a contested area. Additionally, one can, for instance, question the importance of using a method that is consistent with economic theory, when most decisions are made in non-utilitarian contexts. In Sweden, prioritising in health care are not only based on cost-effectiveness but on other principles as well. Sculpher also point out a similar argument when raising the normative question of whether and to what extent productivity costs should be included in economic evaluations "in health care systems based on non-market, egalitarian principles" [30].

\section{Effects}

As mentioned above, QALY is by many a preferred outcome measure and thus described briefly here. QALYs is a measure that comprise both the quality and the length of life. Quality of life is measured on a scale between 0 and 1, where 0 is equal to be dead and 1 is equal of living in perfect health. QALYs are then estimated by multiplying the quality of life with the length of life. Of course, quality of life varies with time and therefore this must be taken into account when estimating total QALYs over time. To elicit values different direct and indirect approaches can be used. The direct methods are standard gamble (SG) [37], time-trade off (TTO) [38] and visual analogue scale (VAS) [39] and are described more in detail elsewhere. Indirect methods are based on different questionnaires, for instance EQ-5D, HUI-3 [40] and SF-6D [41]. These questionnaires result in different health patterns which can be used together with produced value sets to estimate the quality of life for a specific health state.

\section{Health Economic Models}

Health economic models are increasingly used to inform resource allocation decisions. The basic concept is to include all relevant evidence to inform decision making under uncertainty. Often there is discrepancy between evidence 
available from, for example, a randomised controlled trial (RCT) and the information needed to make wise resource allocation decisions. For instance, when decisions are made the long term effects should be taken into account and often RCTs do not provide that information. Hence, this information needs to be collected elsewhere or by making reasonable assumptions and then incorporated in the economic model. More information on modelling in health economic evaluation can be found elsewhere [42, 43].

\section{Prioritisation}

Maximising societal benefit is not always equivalent to maximising health outcome measured in, for instance, the number of QALYs gained. This is because people in general are not utilitarians. This is, for example, reflected in the ethical framework for prioritising in the Swedish health care system, which has been decided by the parliament in Sweden [44]. The framework consist of three ethical principles:

1. Human dignity principle

2. Needs and solidarity principle

3. Cost-effectiveness principle

The human dignity principle states that all individuals has the same value and rights independent of personal characteristics and functions in society. For instance, age, life-style, or economic and social circumstances should not influence the access to health care. The needs and solidarity principle implies that more resources should be allocated to groups that have the poorest quality of life and the most severe diseases. The cost-effectiveness principle is a complement to the other two principles and states that there should be a 
reasonable relationship between costs and effects when choosing between different activities or actions [44].

Health economic evaluation usually focuses on the last ethical principle. Yet there is an ongoing discussion whether to incorporate the other principles in the economic analysis to some extent or not. Today, in Sweden, when reimbursement applications are sent in to the pharmaceutical reimbursement agency, TLV, a cost-effectiveness analysis from a societal perspective is requested [19]. The other ethical principles are weighed against each other in a joint analysis before a reimbursement decision is made.

To just name one example when the ethical principles are in conflict with each other in the economic analysis: the societal perspective, which is the recommended one in Sweden, takes into account if people can go back earlier to work if the sick leave period could be avoided or shortened due to superior treatment. A perspective that value people who can go back to work higher than people who not can go back to work can directly be seen as violating the first ethical principle, in where people should be regarded as equal irrespective of their status and function in society. Williams has previously argued similarly [45].

To conclude, there are other aspects then just maximising health from a utilitarian perspective that should be taken into account when resource allocation decisions are made. The existing ethical principles to guide prioritisations are in part conflicting with each other, which make decision-making a matter of judiciously weighing the advantages against the disadvantages and the trade-off between different ethical principles. 


\section{Systematic Reviews}

Evidence-based medicine (EBM) has been defined as "the conscientious, explicit and judicious use of current best evidence in making decisions about the care of individual patients" [46]. Systematic reviews are a pivotal part in the EBM movement and has consequently been increasingly recognized as an excellent and structured method for evaluating the current state of evidence and identifying gaps of knowledge. Indeed, there are more than one million medical articles published annually [47] and it is not very efficient if everyone wanting to make informed medical decisions should go through all published research by themselves. Therefore systematic reviews fulfils an important function, namely providing distilled, relevant information on specific questions. Additionally, they are very useful in getting a good overview since sometimes it is hard to see the forest for the trees. Furthermore, before embarking on new research it is essential to know what has been done before so that unnecessary research and a waste of resources are avoided. Claxton et al., writes that: "funding additional research without knowledge of existing evidence would seem inappropriate and potentially unethical if an experimental research design is required" [48]. The methodology used in systematic reviews are very fit for the purpose of reviewing previous literature, and hence very useful as point of departure for conducting new research.

Systematic reviews are also a cornerstone in health technology assessments (HTA), which is also becoming increasingly popular. HTA is a framework for analysing specific questions within health care to assist decision-making. HTA has been defined in many ways and this is one definition: "Technology assessment in health care is a multidisciplinary field of policy analysis. It studies the medical, social, ethical, and economic implications of development, 
diffusion, and use of health technology" [49]. Healthcare technology is defined as "prevention and rehabilitation, vaccines, pharmaceuticals and devices, medical and surgical procedures, and the systems within which health is protected and maintained" [49].

Many HTA organisations conduct systematic reviews of economic evaluations as a part of the evaluation because they provide valuable input $[50,51]$. Limitations of such analyses have also been discussed mainly due to difficulties in transferring costs across time and space; there exist however several good reasons for reviewing economic studies [50]. 


\section{AIMS}

The aim of this thesis is to develop new knowledge and improve decision making by elaborating on some of the health economic aspects of injury prevention. These aspects include critical appraisal of the cost-effectiveness of different injury prevention interventions and estimating the societal costs for different types of injuries. Hence, the specific aims of the included studies are as follows:

Study I To elucidate what options are available for a decision-maker, at the municipal level, searching economic evidence on injury prevention interventions a systematic review of the published literature was conducted, with the objective to systematically identify, critically appraise, and compile economic evaluations of injury prevention interventions that could be conducted by municipalities.

Study II To improve the knowledge about the benefits of preventing injuries this study aims at estimating the societal costs for injuries to the head; neck; thorax; abdomen, lower back, lumbar spine and pelvis; shoulder and upper arm; elbow and forearm; wrist and hand; hip and thigh; knee and lower leg; and ankle and foot, respectively. 


\section{MATERIALS AND METHODS}

The health economic aspects that are studied in this thesis are costs for specific injury types and the cost-effectiveness of injury prevention interventions. Two studies are included and different materials and methods were used to answer different research questions both between and within the conducted studies. The methods and materials used are presented for the respective study in this section.

\section{Cost-effectiveness of injury prevention (study I)}

The aim of study I was to critically appraise the published economic evidence of injury prevention interventions by means of a systematic review. The study process included searching, sifting, and quality appraisal of studies and finally a synthesis of the results.

\section{Materials}

The study was based on published literature identified through searches in the databases: PubMed, Embase, Cochrane, and NHS EED. The searches were limited to the last ten years, after considering the trade-off between the resources needed to identify all studies older than ten years and the value of the results of these studies since we know that cost-effectiveness estimates are likely to change over time; for instance, costs, comparison alternative, and other things may change over time and substantially change the results. 


\section{Methods}

\section{Search strategy}

When developing a search strategy there is always a challenge to find the right balance between a strategy that is sensitive enough to capture all relevant articles yet precise enough to exclude as many irrelevant articles as possible. With this in mind a search strategy consisting of different parts was developed to identify articles for potential inclusion based on the research question.

\section{Inclusion and exclusion criteria}

The inclusion and exclusion criteria were as follows:

The study should

- be an economic evaluation of an injury prevention intervention (costeffectiveness, cost-benefit, or cost-utility analysis);

- include some sort of comparison (randomised controlled trial, quasiexperimental, longitudinal cohort, or case-control); a judgement was made if the comparison groups were comparable;

- evaluate an intervention that could be conducted by municipalities; and

- be published in English.

Likewise, there were exclusion criteria and a study was excluded if

- the intervention included any form of medication or drug use;

- it was assessed as not being relevant to the general context; and

- it had an unacceptable quality, appraised by using a checklist previously used by The Swedish Council on Technology Assessment in Health Care [52]. 
Review articles were excluded, although they were later revised to see if they would add any valuable information.

\section{Sifting process}

The sifting process was conducted in three different steps. In the first step titles and abstracts of identified articles were screened for potential inclusion. In the second step, articles that seemed to fulfil the criteria for inclusion and articles where this was unclear were ordered in full and now screened in full for inclusion. In the final step, articles were critical appraised to see if they met the pre specified quality criteria.

\section{Quality assessment}

The interpretation of studies can be difficult; especially, when the quality of a study is deemed too low. Exactly when the quality of a study is too low for the results to be more misleading than informative is a matter of judicious judgment. Different existing checklists can, however, be used to assist in making that judgement. In the conducted review a modified checklist for evaluating health economic studies were used [52], which in turn is based on Drummond's checklist [17]. If more than $50 \%$ of the applicable checklist questions were answered negatively then the study was excluded from the analysis.

\section{Data extraction and synthesis}

All articles that met the inclusion criteria were included in the analysis. Results from the included studies were systematically presented in evidence tables to facilitate comparisons and to get an overview of all results. All cost estimates were also converted to US dollars in price year 2007 by first using GDP deflators and then Purchasing Power Parities (PPPs) as recommended by the 
Campbell \& Cochrane Economics Methods Group [53]. The data needed were retrieved from OECD and IMF $[54,55]$.

\section{The societal costs of injuries (study II)}

The aim of this study was to estimate the societal costs for different injuries. Hence, direct medical costs, costs due to loss in production and the incidences of injuries had to be estimated. Estimations were based on data from Östergötland County Council`s Cost Per Patient Database, Statistics Sweden, and the Swedish Social Insurance Agency.

\section{Materials}

Direct medical costs were estimated by collecting data from Östergötland County Council's Cost Per Patient (CPP) register for the years 2009-2012. The register is described as one of the best and most comprehensive in the country [56]. The education, sex, and age structure in Östergötland county is similar to the national average $[57,58]$. Östergötland's health care costs are similar to the national average [59]. The average number of inhabitants was 425,138 and 9,298,515 for Östergötland and Sweden in 2009, respectively, which corresponds to a share of $4.6 \%$ [60].

The incidences for the different injuries were also estimated by collecting and analysing data from Östergötland County Council’s CPP database. Also, population data from Statistics Sweden was used. 
The loss of production was also estimated by using diagnosis-specific sick leave data from The Swedish Social Insurance Agency (SSIA) for longer periods than 14 days [61] and sick leave data from Statistics Sweden for sick periods shorter than 14 days [62].

\section{Methods}

\section{Incidence of injuries}

The incidence of injuries was estimated by first collecting information about the number of individuals that incurred a diagnosis with a code between S00 and S99 in ICD-10 during the period 2009-20012 from Östergötland County Council's CPP database [63]. Diagnoses were analysed in ten diagnostic groups related to injured body part. Second, the same numbers were collected from private clinics [64]. Finally, the total number of injured individuals per year and diagnostic group were divided by the average number of inhabitants in Östergötland County.

\section{Direct medical costs}

Total medical costs for ICD-10 codes S00-S99 were collected from Östergötland County Council's CPP database for the years 2009-2012 for all types of care inpatient, outpatient, and primary care - and aggregated to total costs irrespective of type of care. Total costs were then divided by the total number unique individuals per diagnostic-group to estimate costs per injury for each diagnostic-group. 


\section{Costs due to lost production}

Costs due to lost production were estimated per diagnostic group and injury by multiplying the total number of sick leave days with the production value of one day, and then divide this with the number of injuries.

The valuation of one sick leave day was made according to the human capital approach $[17,30,65]$, in which production loss is equal to income of employment plus payroll taxes and agreed fees between the labour market parties. Consequently, the average monthly wage was retrieved for the year of 2012 from Statistics Sweden [66]. Agreed fees and payroll taxes amounted to $36.6 \%$ and $47.4 \%$ for blue-collar and white-collar workers respectively in 2009 [67]. In 1999 the share of blue-collar workers was about the same as the share of white-collar workers [68], and therefore the mean, 42\%, was used in the calculations.

In Sweden, the employer is responsible for paying sick pay to employees between day 2 and 14 when on sick leave; and the SSIA pays sickness benefits from 14 days and longer. Hence, diagnosis-specific information on sick leave periods longer than 14 days were available from 2009 and thus retrieved [61]. The number of permanent sick leave days in 2009 was also collected and these origin from individuals injured in 2009 and before. This implies that the prevalence method was used rather than the incidence method when estimating these days. For sick leave periods shorter than 14 days the only available data is estimations made by the Statistics Sweden on the total number of short sick leave period days [62]. There is no information about how many of these are related to injuries and hence, the different ICD groups' share of all sick leave days longer than 14 days was used to make an assumption about how many days of the total sick leave days shorter than 14 days that could have been caused by 
injuries. This is a crude assumption but this method has been used in other areas [69].

\section{Total costs}

The medical costs and the costs due to lost production were added to get total costs per injury for each diagnostic group. To explore the uncertainty around the results some of the included variables were varied $\pm 25 \%$ in one-way sensitivity analyses. 


\section{RESULTS}

This thesis is based on two studies which yielded many results. The principal results from each study are presented in this section.

\section{Cost-effectiveness of injury prevention (study I)}

Twenty articles out of initially 791 identified and screened articles were included in the analysis. The flowchart is shown in Figure 3.

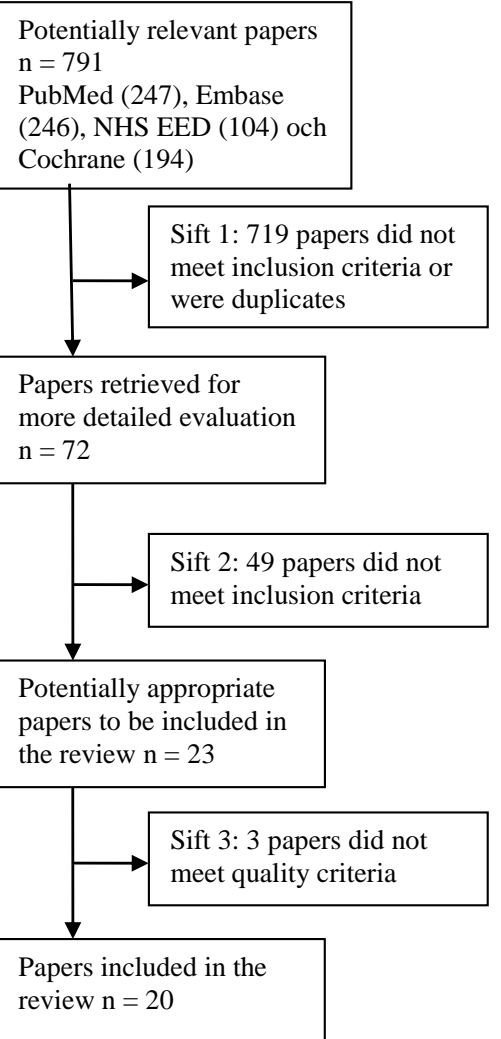

Figure 3: Flow chart showing the sifting process. 
In Table 2 the reviewed studies included in the analysis are shown by setting and result in terms of being net saving, ineffective, or showing an incremental cost per gained health unit. Thirteen studies had results that showed net savings; ten studies had results that showed a cost per health unit gained; and three showed no effect. Of these studies, six studies showed mixed results: both cost saving and a cost per health unit gained. That is why the total number of results were 26 $(13+10+3)$, when the number of included studies were 20 .

The included studies report results from interventions targeting hip fractures [70-84], fire safety [85, 86], traffic safety [87], and sport injuries [88]. One study also encompassed a multi-targeted community-based program [89].

Table 2: Papers reviewed by area and result. Numbers in parentheses show articles with effectiveness data generated within the study.

\begin{tabular}{lllll}
\hline Area & $\begin{array}{l}\text { Number of papers } \mathbf{n} \\
\mathbf{2} \mathbf{2 0}\end{array}$ & $\begin{array}{l}\text { Showing net } \\
\text { savings }\end{array}$ & $\begin{array}{l}\text { Showing a cost per } \\
\text { health score gained }\end{array}$ & Showing no effects \\
\hline $\begin{array}{l}\text { Community-based, } \\
\text { multitargeted }\end{array}$ & 1 & 1 & & \\
$\begin{array}{l}\text { Traffic safety } \\
\text { Smoke alarm }\end{array}$ & 1 & $1^{\mathrm{a}}$ & $1^{\mathrm{a}}$ & 1 \\
Fall reduction & 2 & $1(1)$ & & 1 \\
Hip Protectors & 6 & $2^{\mathrm{b}}$ & $4(3)^{\mathrm{b}}$ & $1(1)$ \\
Sports & 9 & $7^{\mathrm{c}}$ & $4^{\mathrm{c}}$ & \\
\hline Total & 1 & $1(1)^{\mathrm{d}}$ & $1(1)^{\mathrm{d}}$ & $\mathbf{3}$ \\
\hline
\end{tabular}

a One study reported both net savings (time horizon 8 years) and a cost per health score gained (time horizon 1 year) and is thus reported twice [87].

${ }^{b}$ One study reported both net savings (time horizon 10 years) and a cost per health score gained (time horizon 1 year) and is thus reported twice [84].

cIncluded are three articles that report both net savings and a cost per health score gained and are thus reported twice each. One study show net savings without nursing aide time added and a cost per health score gained if added [74]. Another study show net savings for an older population [72]. The third study show net savings for a high-risk population [71].

${ }^{d}$ One study reported both net savings (time horizon "long term") and a cost per health score gained (time horizon 36 weeks) and is thus reported twice [88]. 


\section{The societal costs of injuries (study II)}

The average societal cost was estimated to $€ 2,726$ per injury for diagnoses S00S99. The number of injuries that needed medical attention was estimated at 708,105 in Sweden 2009. Direct medical costs amount to approximately $43 \%$ of the total costs on average. The different costs are shown in Table 3 for the specific diagnostic groups.

Table 3. Total costs per injury in $€$, incidence and total costs of injuries in Sweden.

\begin{tabular}{|c|c|c|c|c|c|}
\hline \multirow{2}{*}{$\begin{array}{l}\text { ICD-group } \\
\text { Injuries to the }\end{array}$} & \multicolumn{2}{|c|}{ Cost categories } & \multirow{2}{*}{$\begin{array}{c}\text { Total cost/ } \\
\text { injury }\end{array}$} & \multirow{2}{*}{$\begin{array}{l}\text { Incidence of } \\
\text { injuries }^{1}\end{array}$} & \multirow{2}{*}{$\begin{array}{c}\text { Total costs } \\
\text { in millions }(\%) \\
\end{array}$} \\
\hline & Direct medical & Production loss & & & \\
\hline head & $1,213(57 \%)$ & 917 (43\%) & 2,130 & 128,655 & $274(14 \%)$ \\
\hline neck & $1,576(10 \%)$ & $13,961(90 \%)$ & 15,537 & 25,929 & 403 (21\%) \\
\hline thorax & $1,201(52 \%)$ & $1,112(48 \%)$ & 2,313 & 31,572 & $73(4 \%)$ \\
\hline $\begin{array}{l}\text { abdomen, lower } \\
\text { back, lumbar spine }\end{array}$ & & & & & \\
\hline and pelvis & $1,933(50 \%)$ & $1,905(50 \%)$ & 3,838 & 22,430 & $86(4 \%)$ \\
\hline $\begin{array}{l}\text { shoulder and } \\
\text { upper arm }\end{array}$ & 1,213 (41\%) & 1,738 (59\%) & 2,951 & 55,697 & $164(9 \%)$ \\
\hline $\begin{array}{l}\text { elbow and } \\
\text { forearm }\end{array}$ & $1,044(47 \%)$ & $1,188(53 \%)$ & 2,232 & 69,684 & $156(8 \%)$ \\
\hline wrist and hand & $568(43 \%)$ & $743(57 \%)$ & 1,311 & 137,306 & $180(9 \%)$ \\
\hline hip and thigh & $4,930(84 \%)$ & $972(16 \%)$ & 5,902 & 36,192 & $214(11 \%)$ \\
\hline knee and lower leg & $1,118(39 \%)$ & $1,713(61 \%)$ & 2,832 & 102,879 & $291(15 \%)$ \\
\hline ankle and foot & $352(39 \%)$ & $540(61 \%)$ & 892 & 97,761 & $87(5 \%)$ \\
\hline Total & $1,168(43 \%)$ & 1,559 (57\%) & 2,726 & 708,105 & 1,931 \\
\hline
\end{tabular}

${ }^{1}$ Estimated on a national level in Sweden (pop 9,298,515 in 2009)

More detailed information about the different cost categories share of the total cost per injury and diagnostic group are also shown in Figure 4.

As can be seen in Table 3 and in Figure 4 there are great variations between different injuries in both the total costs and in each cost categories share of the total costs. For instance, the lowest cost per injury was estimated at around $€$ 892 and the highest at $€ 15,537$ for the diagnostic groups injuries to the ankle 


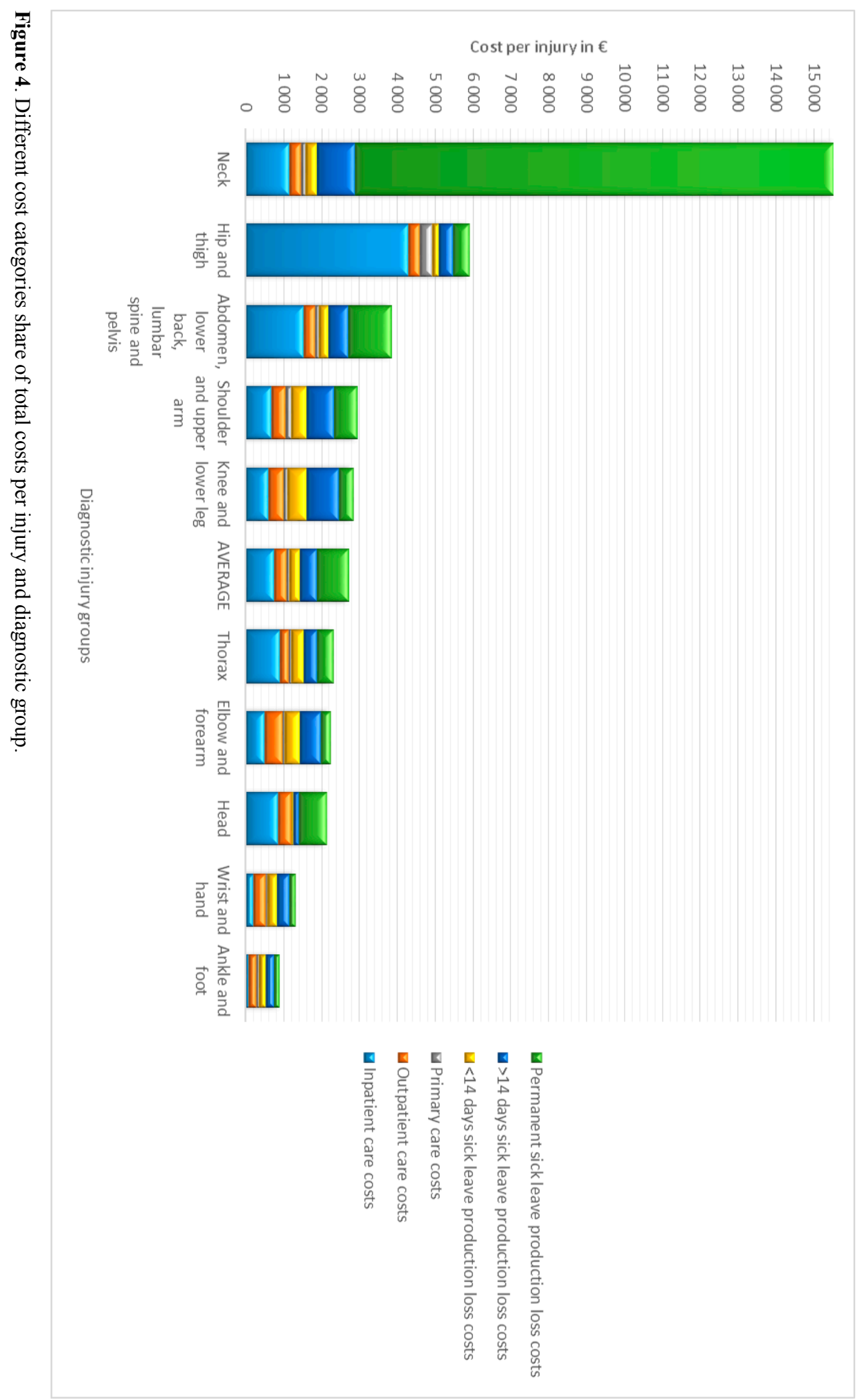


and foot, and injuries to the neck, respectively. In most diagnostic groups the inpatient and permanent sick leave production loss costs are relatively high.

One-way sensitivity analyses were conducted for the average cost per injury and the results are shown in Figure 5. Important variables were varied by $\pm 25 \%$ and the impact on the cost per injury is shown as an incremental increase or decrease for each variable. Of course, the impact differs between diagnostic groups due to the different cost categories share of the total costs as can be seen in Figure 4.

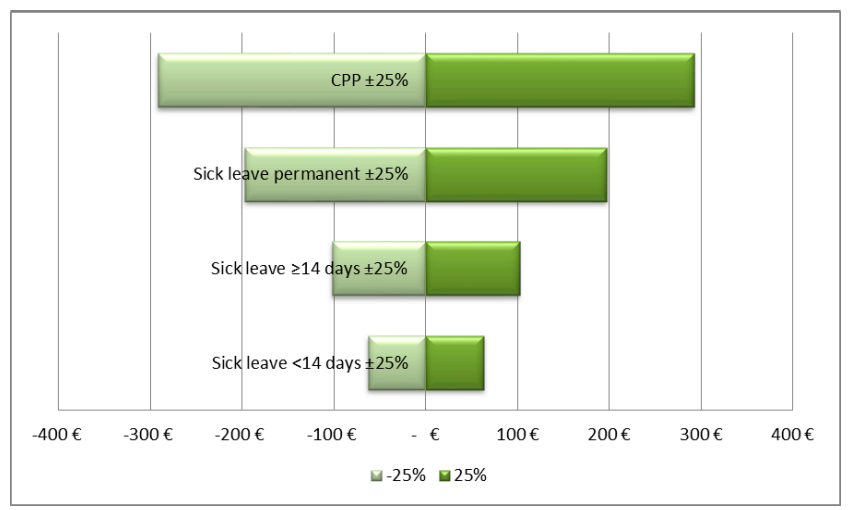

Figure 5. One-way sensitivity analyses showing the impact on the average total cost per injury when varying variables $\pm 25 \%$. 


\section{DISCUSSION}

\section{Main findings}

This thesis shows that injuries are associated with substantial costs to society with great variations between different injuries and that there is a dearth of economic evidence on the cost-effectiveness of injury prevention interventions. Hence, the potential benefits from preventing injuries seems to be high, yet we still do not know enough to be able to come close to maximising health outcomes given the resources available; that is, spend our money wisely.

\section{Strengths and weaknesses}

\section{Cost-effectiveness of injury prevention (study I)}

The advantages of conducting systematic reviews has been described extensively in the literature and is at the centre of evidence-based medicine as well as the core business of an increasing number of HTA organisations. To just give a glimpse of some of the arguments for conducting systematic reviews:

- they provide excellent overviews of the current state of knowledge in specific areas and can inform decisions; 
- they identify gaps of knowledge for future research to target;

- it is good academic practice to make sure that the planned research has not yet been conducted [50]; and

- it may be unethical to not do it if a new experimental design is planned [48].

More specifically, the strengths of the conducted systematic review is that it is comprehensive, including searches in several databases, which minimises the risk of missing important studies. The quality and validity of the included studies are reviewed, which facilitates the interpretations and conclusions of the studies. This can help decision-makers deciding which intervention to implement and this is especially warranted in a world where costs are increasing and budgets become more and more financially constrained. In the end of the day decision-makers need to make and justify decisions on how to allocate societal resources so that maximum outcome is obtained for a confined budget. The studies are also categorised by intervention area which reveals where there are important gaps of knowledge. This is valuable information when deciding where to best allocate scarce research funds.

Anderson discusses the advantages and disadvantages of conducting systematic reviews of economic evaluations [50]. In short, Anderson argue that there is limited value of conducting systematic reviews of economic evaluations if the aim is to provide evidence and inform decisions in a specific context because it is often difficult to transfer results to other contexts. For instance, costs often differ between time and space. However, it is valuable to conduct systematic reviews if the collected information is used with judgement and first utilised after amendments and adjustments to suit your decision context as well as for assisting in the development of a new context specific economic model. 
The study also has limitations. This study was limited to studies including interventions that could be conducted by municipalities. This is a somewhat vague demarcation since it is not always evident when interventions can be conducted by municipalities or not. In this review, this was no major limitation since very few interventions were excluded in the analysis due to this criterion. The excluded interventions were mainly a few studies evaluating different kinds of measures to prevent serious injuries from overturning tractors and injuries among hospital staff caused by syringe needles. It is, however, uncertain if these studies also met all the other inclusion criteria, and thus would have been included in the analysis without the municipality-exclusion-criterion, since they were excluded before investigating the other criteria. There is also a risk of publication bias, that is that negative findings might not have reached publication to the same extend as positive findings [90]. This is of minor importance since no meta-analysis of a cost per QALY gained has been estimated. Even if publication bias is absent estimating a point estimate by conducting a meta-analysis would have been inappropriate since economic evaluations are not easily transferable across space and time, and thus to heterogeneous to include in the same meta-analysis.

Other limitations were that possibly important non peer-reviewed literature could also have been omitted because this study only looked at published peerreviewed literature. Possible human errors due to that one investigator screened and appraised the studies instead of the recommended number: more than one investigator review the literature in parallel $[91,92]$. To minimise the risk of errors due to this, a validation of the quality appraisal was conducted with the help from review reports, written by health economists, in the databases of Centre for Reviews and Dissemination and Euronheed [93], when available; 15 
out of 20 articles were found in these databases and the unanimity was high between the appraisals.

Previous studies, similar to this one [94, 95], and later studies referring to this study [96-99] have not had the same study question as this study had. The overall picture that emerges is, however, in line with the findings in this study, namely: there is a dearth of evidence and that the methodological consistency between studies varies substantially, which calls for a more standardised approach to economic evaluation.

\section{The societal costs of injuries (study II)}

One of the main strengths of this study is that diagnosis-specific sick leave data is used to estimate and include the loss of production in the total costs. This study shows that these costs are substantial and not including them would underestimate the economic impact of injuries. Another strength is that the medical costs were retrieved from a cost per patient data register that has been described as one of the best and the most comprehensive CPP register in Sweden [56]. Estimating the costs for different injuries in the same study with the same methodology is also a strength since this facilitates comparisons between different injuries and cost-effectiveness analyses including interventions targeting different types of injuries. Furthermore, estimating costs for ICD diagnoses facilitates the usefulness of the data in other contexts where only ICD-data is available. Moreover, the study design is a strength since available diagnosis-specific-data from registers are used without the need to follow individual patients manually over time at a great cost. 
This study is not without limitations and the results should therefore be interpreted with caution. One limitation is that not all costs have been included. Costs for pharmaceutical use outside hospital, informal care, transportation, rehabilitation, damage to property, emergency service, police, and long-term care provided by municipalities related to injuries were not included in the analysis. Also, this study only takes into account the reported sick leave days. This implies that the value of any reduction of informal work and lower productivity if people attend work while sick are not included. Hence, both these limitations imply that the real economic costs are likely to be higher than the estimates made in this study. Another limitation is the lack of diagnosis-specific data on sick leave periods shorter than 14 days as described in the method section. Hence, an assumption about the number of days was made by using a methodology used elsewhere [69]. The sensitivity analysis in Figure 5 and the results in Figure 4 shows, however, that this factor does not influence the total costs per injury substantially. Furthermore, analysing ten different diagnostic groups, including ten different diagnoses, may hide great and important variations within groups. To reveal these variations it is possible to study each of the 100 diagnoses separately. The drawback is that a much greater sample is required, especially since many of these diagnoses are very rare. Estimating costs for ten different diagnostic groups reveal more than if just one cost for all injuries had been estimated as most other studies have done [100].

Also, the validity of the results depend on the quality of the data used. Concerning inpatient data, the quality is described in reports by SNBHW. The missing information concerning the main diagnosis is on average less than one percent during the period 2009-2012 [101-104]. Östergötland County Council has also one of the lowest percentage of missing codes concerning external cause of injury and death for individuals having had an injury as a main 
diagnosis [101-104]. Reports on data quality is lacking for outpatient care, primary care and CPP-data [105]. However, there are data from 2012 showing that for primary care the share of doctor visits that was not linked to any diagnosis was $4.2 \%$ in the County of Östergötland [106]. This is at a level that does not affect the results significantly. Wiréhn discuss the quality of Östergötland County Council's CPP-data. She writes that the data quality is continuously improving and that the cost estimates are likely to be underestimated rather than overestimated [107]. Diagnosis-specific sick leave data from SSIA should be of good quality since it is mandatory to obtain a doctor's certificate from the eighth day on sick leave [108]. Short-term sick leave data is of less good quality as described before. Because some variables are not perfectly measured they are varied in the conducted sensitivity analysis to show their impact on the results.

Moreover, analysing the number of injuries by the number of unique individuals during a time period can introduce a minor bias since individuals can incur two or more different and unrelated injuries within the same diagnostic-group during the analysed time period. This will lead to an underestimation of the number of injuries and thus an overestimation of the costs per injury. The magnitude of this problem is unknown; it is, however, plausible to assume that this is a very little problem if a problem at all. Another potentially minor problem that relates to this is that the data on unique individuals were separated between the public and private health care data. This could introduce bias if an individual incurring an injury visit both types of care providers for the same injury because this will be seen as two separate individuals in the separated data. This problem is also likely to be small, since the share of private care (5.6\% on average) is relatively low and it only concerns a portion among those. To minimise the potential bias as consequence of these problems another study design could have been 
employed instead. For instance, an algorithm identifying individuals diagnosed with an S-diagnose for the first time during a time interval and then retrieve all health care contacts and costs on an individual basis related to that diagnose. To analyse individuals at the individual level would, however, need approvals from both an ethical committee and the data provider; and thus it is not evident that the extra effort pays off in relation to the minor improvement in data that possibly can be expected.

\section{Strengths and weaknesses in relation to other studies}

Previous studies have shown limited consistency in which costs to include and the methods used in the analysis [100]. Also, there is a general lack of transparent reporting which aggravates comparisons and adjustments of results. There are also difficulties when comparing costs across time within and between countries, which also Corso et al. acknowledges [109]. Accordingly, there is limited value of discussing specific results in detail in relation to other studies.

A previous literature review found that the total cost per injury case varied between $€ 2,578$ and $€ 4,710$ with a mean value of $€ 3,549$, after adjusting for CPI and PPP from US 2002 dollars to 2012 prices [100]. The inflation was 27.6 percent during the period and the Euro area PPP factor was 0.79 [110,111]. These figures are not directly comparable to the figures in this study since here only ICD codes S00-S99 are studied besides all the other differences in methods between the studies in the field. This study estimated the total costs per injury to $€ 2,726$, which is at the low end of the above range from previous studies. When, for instance, looking more profoundly in the existing Swedish study [112], included in the review, the valuation of one lost day explains a lot of the difference: in that study it is valued at $€ 259$ - with a perspective that "the value of time is equal for all people" - and in this study it is valued at $€ 126$. If the 
value of $€ 259$ had been used in this study the estimated cost of production loss per injury would amount to $€ 4,366$ which is at the high end of the above range. The production loss would also contribute to 73 per cent of the total costs and in the previous Swedish study the share was estimated at 77 per cent [112]. Obviously, there are a lot of other variables that studies handle differently due to a lack of consensus but also due to the perspective of the analysis.

In a Swedish government report the cost of illness for all accidents in Sweden, 2005, were estimated at $€ 6$ billion adjusted to 2012 years prices [5]. The costs include categories that this study did not include which make up to 55 per cent of the total costs. Of these, the major cost categories were property damage and production loss due to mortality [5]. In this study it is argued that if loss of production due to mortality should be included then also the reduction in consumption should be included for consistency reasons [113-116]. Even if the cost estimates in the report in many cases rely on crude assumptions surrounded by great uncertainties the report shows that the societal costs estimated in this study are likely to be conservative because of additional cost categories not included in the analysis.

In relation to many other studies the attached article manuscript report methods and input values transparently which facilitates adjustments if deemed appropriate by the reader for e.g. transferability reasons. Other strengths are that ICD-diagnosis codes are used to identify costs and sick leave days from different registers of relatively good quality based on real data. Attaching costs to ICD-diagnoses facilitate evaluations where incidence figures based on ICD diagnoses are followed over time. One other strength is the relatively good primary and outpatient care data. A difference from other studies is that this study only includes ICD-codes S00-S99 and no other injury diagnoses. 
As a validation of the extrapolation of incidence data from the County of Östergötland to national figures a comparison was made to the figures in a report by the Swedish National Board of Health and Welfare analysing the Injury Database (IDB) [12]. The database has a coverage of about $7 \%$ so the estimated national figures in the report are also extrapolations. The figures in the report were converted to incidences per 100,000 inhabitants by using population statistics from Statistics Sweden [117]. The incidence of both inpatient and outpatient care were very similar to the estimated ones in this study $-1,089$ vs 1,014 and 5,902 vs 6,024 , respectively. No primary care data is available in the IDB.

\section{Future research}

This thesis has developed new knowledge on some of the health economic aspects of injuries and the prevention of them. To get a more complete picture and a better basis for judicious resource allocation decisions there is a need for more research in different areas. More specifically, these areas should comprise:

- the reductions in quality of life for individuals incurring different injuries;

- cost-effectiveness analyses of different injury prevention interventions, including economic models that are populated with the best available evidence;

- marginal effects of altering the intensity and duration of interventions, that is finding the optimal relation between dose-response and costs;

- analysing how injury severity influences the results of the conducted and the above suggested research; 
- studies on the quality of the registry data used in this thesis, and

- explore how the normative trade-off between equity and efficiency influences the results to increase transparency in this matter.

Of course, other research can also be conducted. The results in this thesis also clearly shows that there is a need of more standardised research in economic evaluation. Meanwhile one cannot enough stress the importance of reporting methods and data utilised transparently to facilitate the interpretation and adjustments of results if deemed appropriate to transfer results to other decision contexts. 


\section{CONCLUSIONS}

This thesis has expanded our current knowledge on the costs for different types of injuries and especially revealed great differences in costs between different types of injuries. This knowledge helps us better understand the impact injuries have on the costs and thus the potential gain if succeeding in preventing injuries. Moreover, the study design employed shows that available data in registers could be useful in estimating costs and, hence, make similar designs likely to be cost-effective in relation to other study designs trying to answer similar research questions.

This thesis has also improved our knowledge about the quality and the paucity of economic evidence on the cost-effectiveness of injury prevention interventions. The fact that the existing evidence is often difficult to transfer to other contexts due to differences in methods employed and cost categories included are also highlighted. Thus, this thesis shed light on the limited knowledge we have to mitigate the impact of injuries in society in a costeffective way. This is valuable information for decision-makers because they can start demanding better decision support to improve their decisions.

Future research should focus on evaluating the cost-effectiveness of promising injury prevention interventions to evaluate if these provide value for money. These evaluations need to be transparent enough to enable other people to adjust key variables, and thus making the results relevant to their own setting. To do that, there is also a need of a better understanding of injuries impact on individuals' quality of life, in both short-and long-term. There is also a need for 
making the analyses transparent in which perspective they adopt and the implications, since the choice of perspective is very much relying on ethical normative grounds, which decision-makers should be aware of when making resource allocation decisions. 


\section{ACKNOWLEDGEMENTS}

The writing of this thesis can be compared to a roller coaster ride. I have had support in the ups and downs which have helped me keep on track and finalise this piece of work. Hence, I'm very grateful for all the support I received from different people in the making of this thesis and I would especially like to express my sincere gratitude to the following people:

Kent Lindqvist, my main supervisor, for employing me in a research project, which made it possible to be admitted as a $\mathrm{PhD}$ student, and for valuable research discussions during this time.

Håkan Brodin, supervisor and former colleague at the Swedish National Institute of Public Health for fruitful discussions about health economics and for sharing your extensive experience as a professional health economist.

Lars Lindholm, supervisor, for being a master of succinct and pithy comments besides being a shrewd health economist.

Lars Svensson and Ulrik Lidwall at the Östergötland County Council and the Swedish Social Insurance Agency, respectively, for providing me with invaluable and unpublished database data and patiently answering my questions about the data. 
Emelie Heintz and Thomas Davidson, colleagues at SBU, for fruitful discussions in the end of this journey about issues related to research and health economics.

SBU, The Swedish Council on Health Technology Assessment, my employer for supporting me during the last year, which made it possible to free the time needed to walk the extra mile and finalise this work.

The Swedish Contingencies Agency for financial support in the making of paper I.

Finally, my family which has grown from two to four people including me during this period. Without the support from them it would have been impossible to write this thesis because it has to a great extent been written in spare time. 


\section{REFERENCES}

1. World Health Organization. Injuries 2014 [2014-03-26]. Available from: http://www.who.int/topics/injuries/en/.

2. World Health Organisation. World Health Statistics 2009. Geneva 2009.

3. Statistikdatabas för dödsorsaker [Statistics Database of causes of death] [Internet]. 2014 [cited 2014-03-14]. Available from: http://www.socialstyrelsen.se/statistik/statistikdatabas.

4. Schyllander J, Nationellt centrum för lärande från olyckor, Sverige. Statens räddningsverk. Olycksfall bland barn och ungdomar [Accidents among children and adolescents]. Karlskoga: Nationellt centrum för lärande från olyckor (NCO); Räddningsverket, 2007.

5. MSB [Swedish Civil Contingencies Agency]. Samhällets kostnader för olyckor [Society's costs for accidents]. Karlstad: 2012 MSB 340.

6. Currie G, Kerfoot KD, Donaldson C, Macarthur C. Are cost of injury studies useful? Injury prevention : journal of the International Society for Child and Adolescent Injury Prevention. 2000;6(3):175-6.

7. Pless IB, Hagel BE. Injury prevention: a glossary of terms. Journal of epidemiology and community health. 2005;59(3):182-5.

8. Baker SP, Baker SP. The injury fact book. 2 ed. New York; Oxford: Oxford University Press; 1992.

9. World Health Organization. ICD-10 Version:2010 2010 [cited 2014 201403-14]. Available from:

http://apps.who.int/classifications/icd10/browse/2010/en.

10. Pickett JP. The American Heritage dictionary of the English language. 4th ed. Boston: Houghton Mifflin; 2000.

11. Diagnoses in in-patient care [Internet]. 2014 [cited 2014-03-27]. Available from: http://www.socialstyrelsen.se/statistik/statistikdatabas. 
12. The Swedish National Board of Health and Welfare. Skadehändelser som föranlett läkarbesök vid akutmottagning: Statistik från Socialstyrelsens Injury Database (IDB) Sverige, 2010 [Injuries that led to medical attention at the hospital emergency department: Statistics from Injury Database]. Stockholm: Socialstyrelsen, 2011.

13. Gyllensvärd $\mathrm{H}$. The societal costs of injuries: estimating the incidence and cost for different types of injuries in Sweden. Manuscript submitted for publication. 2014.

14. Lindqvist K. Motala Municipality - a sustainable Safe Community in Sweden. International journal of injury control and safety promotion. 2012;19(3):249-59.

15. Nilsen P. Opening the black box of community-based injury prevention programmes : towards improved understanding of factors that influence programme effectiveness. Linköping: Univ.; 2006.

16. Folland S, Goodman AC, Stano M. The economics of health and health care. 5. ed. Upper Saddle River, N.J.: Pearson Prentice Hall; 2007.

17. Drummond MF. Methods for the economic evaluation of health care programmes. 3 ed. Oxford: Oxford University Press; 2005.

18. National Institute for Health and Care Excellence. Guide to the methods of technology appraisal 2013. London: 2013.

19. The Pharmaceutical Benefits Board (TLV). General guidelines for economic evaluations from the Pharmaceutical Benefits Board (LFNAR 2003:2). 2003.

20. Brouwer W, Rutten F, Koopmanschap M. Costing in economic evaluation. In: Drummond MF, McGuie A, editors. Economic evaluation in health care: merging theory with practice. Oxford: Oxford University Press; 2001.

21. Gold MR, Siegel JE, Russell LB, Weinstein MC. Cost-Effectiveness in Health and Medicine. New York: Oxford Univ. Press; 1996.

22. Claxton K, Walker S, Palmer S, Sculpher M. Appropriate perspectives for health care decisions. York: 2010. 
23. Johannesson M, O'Conor RM. Cost-utility analysis from a societal perspective. Health policy. 1997;39(3):241-53.

24. Jonsson B. Ten arguments for a societal perspective in the economic evaluation of medical innovations. The European journal of health economics : HEPAC : health economics in prevention and care. 2009;10(4):357-9.

25. Williams A. Economics of coronary artery bypass grafting. British medical journal. 1985;291(6491):326-9.

26. Rice DP. Cost of illness studies: what is good about them? Injury prevention : journal of the International Society for Child and Adolescent Injury Prevention. 2000;6(3):177-9.

27. Hodgson TA, Meiners MR. Cost-of-illness methodology: a guide to current practices and procedures. The Milbank Memorial Fund quarterly Health and society. 1982;60(3):429-62.

28. Segel JE. Cost-of-Illness Studies: A Primer: RTI International RTI-UNC Center of Excellence in Health Promotion Economics; 2006. Available from: http://www.rti.org/publications/abstract.cfm?pubid=6042.

29. Tarricone R. Cost-of-illness analysis. What room in health economics? Health policy. 2006;77(1):51-63.

30. Marc Sculpher. The role and estimation of productivity costs in economic evaluation. In: Drummond MF, McGuie A, editors. Economic evaluation in health care: merging theory with practice. Oxford: Oxford University Press; 2001.

31. Rice DP, Cooper BS. The economic value of human life. American journal of public health and the nation's health. 1967;57(11):1954-66.

32. Koopmanschap MA, Rutten FF. Indirect costs in economic studies: confronting the confusion. PharmacoEconomics. 1993;4(6):446-54.

33. Koopmanschap MA, Rutten FFH, van Ineveld BM, van Roijen L. The friction cost method for measuring indirect costs of disease. Journal of health economics. 1995;14(2):171-89. 
34. Koopmanschap MA, van Ineveld BM. Towards a new approach for estimating indirect costs of disease. Social science \& medicine. 1992;34(9):1005-10.

35. Johannesson M, Karlsson G. The friction cost method: a comment. Journal of health economics. 1997;16(2):249-55; discussion 57-9.

36. Nicholson S, Pauly MV, Polsky D, Sharda C, Szrek H, Berger ML. Measuring the effects of work loss on productivity with team production. Health economics. 2006;15(2):111-23.

37. Von Neumann J, Morgenstern O. Theory of games and economic behavior. Princeton, NJ US: Princeton University Press; 1944.

38. Torrance GW, Thomas WH, Sackett DL. A utility maximization model for evaluation of health care programs. Health services research. 1972;7(2):118-33.

39. Patrick DL, Bush JW, Chen MM. Methods for measuring levels of wellbeing for a health status index. Health services research. 1973;8(3):22845.

40. Furlong WJ, Feeny DH, Torrance GW, Barr RD. The Health Utilities Index (HUI) system for assessing health-related quality of life in clinical studies. Annals of medicine. 2001;33(5):375-84.

41. Brazier J, Roberts J, Deverill M. The estimation of a preference-based measure of health from the SF-36. Journal of health economics. 2002;21(2):271-92.

42. Briggs A, Claxton K, Sculpher M. Decision Modelling for Health Economic Evaluation: Oxford University Press; 2006.

43. Kuntz KM, Weinstein MC. Modelling in economic evaluation. In: Drummond MF, McGuie A, editors. Economic evaluation in health care: merging theory with practice. Oxford: Oxford University Press; 2001.

44. Utredningen om prioriteringar inom hälso- och sjukvården [The study on priorities in health care]. Vårdens svåra val: slutbetänkande [The difficult choices within healthcare: final report]. Stockholm: Fritze; 1995. 
45. Williams A. Cost-effectiveness analysis: is it ethical? Journal of medical ethics. 1992;18(1):7-11.

46. Sackett DL, Rosenberg WM, Gray JA, Haynes RB, Richardson WS. Evidence based medicine: what it is and what it isn't. Bmj. 1996;312(7023):71-2.

47. Statens beredning för medicinsk utvärdering [Swedish Council on Health Technology Assessment]. Utvärdering av metoder i hälso- och sjukvården: en handbok [Evaluation of methods in health care: a handbook]. Stockholm: Statens beredning för medicinsk utvärdering (SBU); 2013.

48. Claxton K, Griffin S, Koffijberg H, McKenna C. Expected health benefits of additional evidence: Principles, methods and applications. 2013.

49. International Network of Agencies for Health Technology Assessment (INAHTA). HTA Resources Definitions 2014 [2014-03-15]. Available from: http://www.inahta.org/HTA/.

50. Anderson R. Systematic reviews of economic evaluations: utility or futility? Health economics. 2009;19(3):350-64.

51. National Institute for Health and Clinical Excellence. The guidelines manual. London: 2012.

52. The Swedish Council on Technology Assessment in Health Care (SBU). Open Angle Glaucoma. Diagnosis, Follow-up, and Treatment. Stockholm 2008.

53. The Campbell Collaboration Economics Methods Policy Brief 2008. Available from:

http://camp.ostfold.net/artman2/uploads/1/Economic_Methods_Policy_Br ief.pdf.

54. IMF. World Economic Outlook Database 2009. Available from: http://www.imf.org/external/pubs/ft/weo/2009/01/weodata/index.aspx.

55. OECD. Purchasing Power Parities Data. Available from: http://www.oecd.org/document/47/0,3343,en_2649_34357_36202863_1_ 1_1_1,00.html\#historicalppp. 
56. Landstinget i Östergötland [Östergötland County Council]. KPPprinciper, Landstinget i Östergötland, version 1 [CPP-principles, Östergötland County Council, version 1]. 2013.

57. Population 16-95+ years of age by region, level of education, age and sex. Year 2008 - 2012 [Internet]. 2014 [cited 2014-02-25]. Available from: http://www.scb.se/en_/Finding-statistics/Statistical-Database/Selectvariables/?px tableid=ssd_extern\%3aUtbBefRegion\&rxid=15bd1584$\underline{3 c 3 b-41 e 4-81 a 4-2 f 8279 d a c 917 . ~}$

58. Statistics Sweden. Sveriges befolkning, kommunala jämförelsetal, 31 december 2009 [Swedish population, municipal comparatives, December 31, 2009] 2014 [2014-02-25]. Available from: http://www.scb.se/sv_/Hitta-statistik/Statistik-efteramne/Befolkning/Befolkningenssammansattning/Befolkningsstatistik/25788/25795/.

59. Cost per health contact in primary care; Cost per DRG points [Internet]. 2014 [cited 2014-03-02]. Available from: http://www.kolada.se/index.php?page=workspace/nt.

60. Statistics Sweden. Population in the country, counties and municipalities on 31/12/2009 and Population Change in 2009 (corrected 2010-03-26) 2014 [2014-03-02]. Available from: http://www.scb.se/en_/Findingstatistics/Statistics-by-subject-area/Population/Populationcomposition/Population-statistics/Aktuell-Pong/25795/.

61. The Swedish Social Insurance Agency. Vad kostar olika sjukdomar i sjukförsäkringen? [What do different diseases costs in the public health insurance]. 2011.

62. Statistics Sweden. Personal communication: Total estimated number of short sick leave days for 2009, excel file with data. 2012.

63. Östergötland County Council, Svensson L. Personal communication: CPP-costs for S-diagnoses excel file with data. 2013.

64. Östergötland County Council, Svensson L. Personal communication: CPP-costs for S-diagnoses excel file with data. 2014.

65. Burton AW. The Valuation of Human Capital. Journal of Political Economy. 1961;69(5):425-36. 
66. Statistics Sweden. Löneutveckling 1992-2012 [wage trend 1992-2012]

2012 [2013-11-05]. Available from: http://www.scb.se/sv_/Hitta-

statistik/Statistik-efter-amne/Arbetsmarknad/Loner-och-

arbetskostnader/Lonestrukturstatistik-hela-ekonomin1/14367/14374/.

67. Ekonomifakta. Arbetsgivaravgift [payroll tax] 2013 [2013-09-24]. Available from:

http://www.ekonomifakta.se/sv/Fakta/Arbetsmarknad/Arbetsgivaravgift/ Arbetsgivaravgift/.

68. SOU. Avdragsrätt för fackföreningsavgifter: betänkande [Deduction of union dues: report]. Statens offentliga utredningar, 2000:65. Stockholm: Fritzes offentliga publikationer; 2000.

69. Tinghog G, Carlsson P, Synnerstad I, Rosdahl I. Societal cost of skin cancer in Sweden in 2005. Acta Derm Venereol. 2008;88(5):467-73.

70. Colon-Emeric CS, Datta SK, Matchar DB. An economic analysis of external hip protector use in ambulatory nursing facility residents. Age and Ageing. 2003;32(1):47-52.

71. Fleurence RL. Cost-effectiveness of fracture prevention treatments in the elderly. International journal of technology assessment in health care. 2004;20(2):184-91.

72. Honkanen LA, Mushlin AI, Lachs M, Schackman BR. Can hip protector use cost-effectively prevent fractures in community-dwelling geriatric populations? J Am Geriatr Soc. 2006;54(11):1658-65.

73. Meyer G, Wegscheider K, Kersten JF, Icks A, Muhlhauser I. Increased use of hip protectors in nursing homes: economic analysis of a cluster randomized, controlled trial. J Am Geriatr Soc. 2005;53(12):2153-8.

74. Sawka AM, Gafni A, Boulos P, Beattie K, Papaioannou A, Cranney A, et al. Could a policy of provision of hip protectors to elderly nursing home residents result in cost savings in acute hip fracture care? The case of Ontario, Canada. Osteoporos Int. 2007;18(6):819-27.

75. Segui-Gomez M, Keuffel E, Frick K. Cost and effectiveness of hip protectors among the elderly. International journal of technology assessment in health care. 2002;18(1):55-66. 
76. Singh S, Sun HY, Anis AH. Cost-effectiveness of hip protectors in the prevention of osteoporosis related hip fractures in elderly nursing home residents. Journal of Rheumatology. 2004;31(8):1607-13.

77. Waldegger L, Cranney A, Man-Son-Hing M, Coyle D. Cost-effectiveness of hip protectors in institutional dwelling elderly. Osteoporos Int. 2003; 14(3):243-50.

78. van Schoor NM, de Bruyne MC, van der Roer N, Lommerse E, van Tulder MW, Bouter LM, et al. Cost-effectiveness of hip protectors in frail institutionalized elderly. Osteoporos Int. 2004;15(12):964-9.

79. Campbell AJ, Robertson MC, La Grow SJ, Kerse NM, Sanderson GF, Jacobs RJ, et al. Randomised controlled trial of prevention of falls in people aged $>/=75$ with severe visual impairment: the VIP trial. Bmj. 2005;331(7520):817.

80. Hendriks MRC, Evers SMAA, Bleijlevens MHC, Van Haastregt JCM, Crebolder HFJM, Van Eijk JTM. Cost-effectiveness of a multidisciplinary fall prevention program in community-dwelling elderly people: A randomized controlled trial (ISRCTN 64716113). International journal of technology assessment in health care. 2008;24(2):193-202.

81. Johansson P, Sadigh S, Tillgren P, Rehnberg C. Non-pharmaceutical prevention of hip fractures - A cost-effectiveness analysis of a community-based elderly safety promotion program in Sweden. Cost Eff Resour Alloc. 2008;6(-):11.

82. Robertson MC, Devlin N, Scuffham P, Gardner MM, Buchner DM, Campbell AJ. Economic evaluation of a community based exercise programme to prevent falls. Journal of epidemiology and community health. 2001;55(8):600-6.

83. Salkeld G, Cumming RG, O'Neill E, Thomas M, Szonyi G, Westbury C. The cost effectiveness of a home hazard reduction program to reduce falls among older persons. Aust N Z J Public Health. 2000;24(3):265-71.

84. Smith RD, Widiatmoko D. The cost-effectiveness of home assessment and modification to reduce falls in the elderly. Aust N Z J Public Health. 1998;22(4):436-40. 
85. Ginnelly L, Sculpher M, Bojke C, Roberts I, Wade A, Diguseppi C. Determining the cost effectiveness of a smoke alarm give-away program using data from a randomized controlled trial. Eur J Public Health. 2005; 15(5):448-53.

86. Haddix AC, Mallonee S, Waxweiler R, Douglas MR. Cost effectiveness analysis of a smoke alarm giveaway program in Oklahoma City, Oklahoma. Injury Prevention. 2001;7(4):276-81.

87. Goldstein JA, Winston FK, Kallan MJ, Branas CC, Schwartz JS. Medicaid-Based Child Restraint System Disbursement and Education and the Vaccines for Children Program: Comparative Cost-effectiveness. Ambulatory Pediatrics. 2008;8(1):58-65.

88. Verhagen EALM, Van Tulder M, Van Der Beek AJ, Bouter LM, Van Mechelen W. An economic evaluation of a proprioceptive balance board training programme for the prevention of ankle sprains in volleyball. $\mathrm{Br} \mathrm{J}$ Sports Med. 2005;39(2):111-5.

89. Lindqvist K, Lindholm L. A cost-benefit analysis of the community-based injury prevention programme in Motala, Sweden - a WHO Safe Community. Public Health. 2001;115(5):317-22.

90. Polit DF, Beck CT. Nursing research: generating and assessing evidence for nursing practice. Philadelphia: Wolters Kluwer Health/Lippincott Williams \& Wilkins; 2008.

91. Higgins JPT, Green S, editors. Cochrane handbook for systematic reviews of interventions. Version 5.1.0 [updated March 2011] ed 2011.

92. Centre for Reviews and Dissemination. Systematic Reviews: CRD's guidance for undertaking systematic reviews in health care. York: York Publishing Services Ltd; 2009.

93. CRD Database [Internet]. 2014. Available from: http://www.crd.york.ac.uk/CRDWeb/.

94. Miller TR, Levy DT. Cost-outcome analysis in injury prevention and control: eighty-four recent estimates for the United States. Med Care. 2000;38(6):562-82. 
95. Smith RD, Fordham RJ. Economics of fall prevention programs: Evidence and research priorities. Expert Rev Pharmacoecon Outcomes Res. 2001;1(1):59-67.

96. Grimes CE, Henry JA, Maraka J, Mkandawire NC, Cotton M. Costeffectiveness of surgery in low- and middle-income countries: a systematic review. World journal of surgery. 2014;38(1):252-63.

97. Ho KM, Geelhoed E, Gope M, Burrell M, Rao S. An injury awareness education program on outcomes of juvenile justice offenders in Western Australia: an economic analysis. BMC health services research. 2012;12(1):279.

98. Polinder S, Segui-Gomez M, Toet H, Belt E, Sethi D, Racioppi F, et al. Systematic review and quality assessment of economic evaluation studies of injury prevention. Accident; analysis and prevention. 2012;45:211-21.

99. Wesson HK, Boikhutso N, Bachani AM, Hofman KJ, Hyder AA. The cost of injury and trauma care in low-and middle-income countries: a review of economic evidence. Health policy and planning. 2013:czt064.

100. Nilsen P, Hudson D, Lindqvist K. Economic analysis of injury prevention--applying results and methodologies from cost-of-injury studies. International journal of injury control and safety promotion. 2006;13(1):7-13.

101. The Swedish National Board of Health and Welfare. Skador och förgiftningar behandlade i sluten vård 2009 [Injuries and Poisoning treated in inpatient care 2009]. Stockholm: Socialstyrelsen; 2010.

102. The Swedish National Board of Health and Welfare. Skador och förgiftningar behandlade i sluten vård 2010 [Injuries and Poisoning treated in inpatient care 2010]. Stockholm: Socialstyrelsen; 2011.

103. The Swedish National Board of Health and Welfare. Skador och förgiftningar behandlade i sluten vård 2011 [Injuries and Poisoning treated in inpatient care 2011]. Stockholm: Socialstyrelsen; 2012.

104. The Swedish National Board of Health and Welfare. Skador och förgiftningar behandlade i sluten vård 2012 [Injuries and Poisoning treated in inpatient care 2012]. Stockholm: Socialstyrelsen; 2013. 
105. Östergötland County Council, Onelöv E. Personal communication: Questions about data quality. 2014.

106. Östergötland County Council, Svensson L. Personal communication: Questions about data quality. 2014.

107. Wiréhn A-B. A Data-Rich World: Population based registers in healthcare research. Linköping: Linköping University, Health and Society; 2007.

108. Swedish Social Insurance Agency. About doctor's certificate 2014 [updated 2014-04-13]. Available from:

http://www.forsakringskassan.se/arbetsgivare/sjukfranvaro/om_lakarintyg /lut/p/b1/hY5RC4IwFIV_Ud7rAtkeFbIZ1IsP2V7kBjqWusVcgv-Bb1m52D7xwOKGhAWVqMpmCcpfHDKms5w3NRpDnyGjlWQopDKdhRYB aFWxTwR3L81z-B6oeE_LOLszYL-S6ZH6h92QjuMRN7UgDeWPDquEKamtQsv22kJbsK2w8vkg3dfCcmrWudvkb CU01Rw!!/d14/d5/L01DU1EvUU5RSy80SIVFL2Vu/.

109. Corso P, Finkelstein E, Miller T, Fiebelkorn I, Zaloshnja E. Incidence and lifetime costs of injuries in the United States. Injury prevention : journal of the International Society for Child and Adolescent Injury Prevention. 2006;12(4):212-8.

110. OECD. PPPs and exchange rates 2013 [2013-09-24]. Available from: http://stats.oecd.org/Index.aspx?DataSetCode=MEI_PRICES\#.

111. U.S. Department Of Labor Bureau of Labor Statistics. Consumer Price Index 2013 [updated 2013-10-21]. Available from: http://www.bls.gov/cpi/tables.htm.

112. Lindqvist KS, Brodin H. One-year economic consequences of accidents in a Swedish municipality. Accid Anal Prev. 1996;28(2):209-19.

113. Ekman M. Studies in health economics: Modelling and data analysis of costs and survival: Stockholm School of Economics; 2002.

114. Johannesson M, Meltzer D. Editorial: Some reflections on cost-effectiveness analysis. Health economics. 1998;7(1):1-7.

115. Meltzer D. Accounting for future costs in medical cost-effectiveness analysis. Journal of health economics. 1997;16(1):33-64. 
116. Meltzer D, Johannesson M. Inconsistencies in the "societal perspective" on costs of the Panel on Cost-Effectiveness in Health and Medicine. Medical decision making : an international journal of the Society for Medical Decision Making. 1999;19(4):371-7.

117. Statistics Sweden. Swedish Population (in one-year groups) 1860-2012 2013 [2013-11-01]. Available from: http://www.scb.se/en_/Findingstatistics/Statistics-by-subject-area/Population/Populationcomposition/Population-statistics/Aktuell-Pong/25795/ 


\section{Papers}

The articles associated with this thesis have been removed for copyright reasons. For more details about these see:

http://urn.kb.se/resolve?urn=urn:nbn:se:liu:diva-106227 